\title{
Knowledge, Attitudes and Practices of Poultry Farms' Workers about Occupational Health Hazards at Assiut District
}

\author{
Eman R. Mohamed, Mohammed H. Qayed, Soad S. Bayomi, Asmaa K. Hassan. \\ Nursing Specialist at Technical Institution of Nursig, Assiut University. \\ Professor of Public Health and Community Medicine, Faculty of Medicine, Assiut University. \\ Assistant Professor of Community Health Nursing, Faculty of Nursing, Assiut University. \\ Lecturer of Community Health Nursing, Faculty of Nursing, Assiut University.
}

\begin{abstract}
Background: The atmosphere in poultry houses, particularly where ventilation is limited, can adversely affect human health. Aim of study: Assess knowledge, attitude and practice of participants at poultry farms regarding occupational health hazards Methods: cross sectional study was used in this study concluded 400 participants from Assuit district One tool used; Interview questionnaire developed to collect data. It consist of five parts first part to assess socio-demographic characteristics, second part to assess medical history, third part to assess workers' knowledge, fourth part to assess practice of workers and fifth part is likert rating scale to assess workers' attitude. Results: Shows that $53.8 \%$ were $20-40$ years, $40.2 \%$ had secondary school, $71.7 \%$ had poor knowledge about occupational health hazards at poultry farms, and $34.8 \%$ had positive attitude towards occupational health hazards at poultry farms. Conclusion: There was poor knowledge among poultry workers in Assuit distract while more than one third had positive attitude towards their work. Recommendations:. Workers must wear appropriate personal protective equipment such as gloves, mask and aprons.
\end{abstract}

Key words: Workers, Hazards, Knowledge, Attitudes \& Practices.

\section{Introduction}

The poultry industry is one of the most important animal production industries and contributes to approximately $10 \%$ of the all meat and eggs produced in the world each year (Wei et al., 2006).

The commercial poultry sector in Egypt was estimated to be 850 million birds in 2006, where the majority of farms are small-scale units $(5000-20000$ birds) with poor or no biosecurity and usually used for broiler and layer poultry production. Conversely, the breeders and grandparent farms have strict biosecurity measures with all-in all-out production systems (Abdelwhab and Hafez, 2011).

Poultry processing is an occupation, like farm work, that poses substantial risk for injury and illness to its largely racial and ethnic minority workforce. In 2006, the Bureau of Labor Statistics (BLS) estimates indicated that more than 15,000 poultry workers nationwide reported occupational injuries or illnesses for a rate of 6.6 per 100 full-time workers, more than 10,000 of which were severe enough to miss work or require restricted activity. The nonfatal injury rate among poultry-processing workers was 5.3 per 100 full-time workers, and the illness rate was $1.3 / 100$ (Bureau of Labor Statistics, 2007).

Poultry workers who spend the most time in poultry farms and therefore experience the greatest amount of exposure are at greatest risk. These include poultry caretakers, farm managers and flock supervisors. Another category of workers at risk include poultry catchers, who harvest the birds for transportation to processing plants. The atmosphere in poultry farms usually contains significant levels of agricultural dust and toxic gases, which put the workers at a health risk (OSHA, 2007).

Ventilation in the houses accommodating poultry is generally intended to maintain a comfortable atmosphere for the birds. The dust generated during tasks such as spreading clean litter or removing manure may be slightly reduced by the operation of shed ventilation systems. Some reports suggested that farm managers were reluctant to operate ventilation for the benefit of contractors, probably because of energy costs. Where exposure is recognised as potentially harmful, reliance is usually placed on respiratory protection of one sort or another( Liebers, 2007).

Occupational hazards which can be classified into accident, physical chemical, biological, psychosocial, economic hazards. Accident Hazards include Sprains and stains from slips, trips and falls when carrying heavy loads (bags of feed), working in congested and slippery areas soiled. Eye and skin irritation from contamination of broken skin or from splashing of irritants, allergens, other hazardous fluids (disinfectants) during vaccination/medicating (in feed / water ), mixing of feed transporting feed/medicines, or spraying vaccines, disinfectants and fumigating 
agents and burns from exposure to hot surfaces (e.g. incubators, debarking tools) (Odunsi et al, 2005).

The occupational health nurse is skilled in primary prevention of injury or disease. The nurse may identify the need for, assess and plan interventions for example modify working environments, systems of work or change working practices in order to reduce the risk of hazardous exposure.

Occupational health nurses can play an essential role in health assessment for fitness to work, pre employment or pre placement examinations, periodic health examinations and individual health assessments for lifestyle risk factors (Mary, 2011).

\section{Significant of the study}

Poultry processing workers have some of the highest occupational health risks. A study conducted in Sharkia Governorate, 2011 reported that complaints among poultry farm workers were ocular complaints (55.4\%), followed by gastrointestinal (48.2\%), respiratory $(41.8 \%)$, and dermatological $(38.1 \%)$ complaints. Also, $46.3 \%$ of the exposed group had more than one complaint (El-Saadawy et al., 2011).

\section{Subjects and methods: Research design}

A cross-sectional research design was used in this study

\section{Study Setting}

The present study was conducted at all licensed poultry farms located in Assiut district, Assiut Governorate from the first of May to end of July,2013. The researcher had obtained a list of licensed farms located in Assiut district from the Agriculture Directorate of Assiut Governorate. The researcher had access only to 87 farms with response rate $74.4 \%$ out of the total licensed farms (117 farms), the remaining 30 farms were out of reached because they were either closed or their owners refused to participate in the study.

The study was conducted at Assuit Universtiy poultry farms and 13 villages of Assiut district (i.e., Manqabad, Elwan, El-Bora, Bani Ghaleb, Bani Hussein, Awlad Rayek, Masra'a, Nagoa Bani Hussein, Nagae Sabae, Nagae Abd El-Rasool, ElEsaweya Reefa, and Elzzawya)

\section{Study subjects}

All people who take care the poultry farms located in Assiut district of Assiut Governorate were eligible to be included in the study and composed what is known as sample frame (400 persons).

\section{Sampling technique}

The researcher recruited all concerned persons were accessible during field visits for data collection from the study settings.

\section{Study tools}

Is a interview questionnaire was developed by the researcher under the supervision of the supervisors and which was used as an instrument for data collection. Direct interviews were undertaken at the poultry farms of the study participants. The language of the questionnaire was Arabic. The questionnaire sheets was included multiple choice questions (MCQ), open and closed ended questions. It consisted of the following:

I- The tool Interview questionnaire sheet: it included five parts

1-The first part was designed to assess sociodemographic characteristics

Such as name, age, sex, educational level, marital status, current jobs, nature of work, years of work and hours of work.

2-The second part was designed to assess medical history:-

This part included questions about the presence of disease in all workers such as respiratory disease, skin disease, musculoskeletal disease, digestive system disease presence of other disease .

3-The third part designed to assess workers' knowledge about:-

Occupational health hazards, zoonitic diseases transmitted from chickens to human, signs and symptoms of sick birds, modes of transmission to human, hazards of poultry dust and noise and how protected human from these disease.

4- The fourth part was designed to assess practice of workers by asking like:-

Wearing special clothes during work, use protective tools, hand washing, vaccination of birds, eating during work inside poultry disinfected clothes of work, dealing with sick birds, dealing with poultry refuses.

\section{5-The fifth part is Likert rating scale:}

It was used to assess workers' attitude towards occupational health hazards at poultry farms. It consists of 23 statements expression point of view . The responses were on a three - point psychometric scale (agree, neutral, and disagree ) instead of (very strong agreement, neither disagree nor agree, and very strong disagreement). The scoring was reversed for negative statements. The total score was calculated by summing up scores and converting them into a percent score. Workers' attitude was considered positive if the score $60 \%$ 
and more and negative attitude if the score was less than $60 \%$ (Caracciolo et al, 2011).

\section{Statistical analysis and scoring system}

Analysis of the result was done by a computer program .Excel 2003 program is used for data entry. The statistical analysis was done by using Software Package for Social Science (SPSS), version 16.0. Descriptive statistics were calculated i.e frequency, percentage, mean, and standard deviation. Variables were compared using chi-square test. Statistical significance was considered at $\mathrm{p}$. value $<0.05$.scoring system for Knowledge was as follow The researcher in collaboration with supervisors designed and adopted a scoring system for estimation of the correct answers of Knowledge questions of the present study. According to this system, a scoring system was designed for the assessment of knowledge. One grade was given for each correct answer and grade of zero was given for an incorrect answer. The scores of each item were summed and then converted into a percent score. Poor knowledge: score of less than 50\%), Satisfactory knowledge: if score is $50-70 \%$ and Good knowledge: if score is more than $70 \%$.

\section{Methodology:}

\section{I- Administrative phase:}

A request from the Dean of the Faculty of Nursing, Assiut University had been submitted to all concerned bodies to obtain an approval to facilitate carrying out this study. The Head of Assiut Agriculture Directorate offered a list of licensed poultry farms located in Assiut district, and issued an approval letters especially to mangers of the governmental farms to cooperate with the researcher.

\section{II- Pilot Study}

A pilot study was carried out before starting data collection and it was carried out on 40 workers who were included in the study. To estimate the time required for filling up the forms and make any modification .

\section{III-Data collection Phase:}

\section{Ethical Consideration}

All persons at the study settings were eligible to participate in the study. The researcher invited them to participate in the study after explanation of the study aims. Those who agreed to participate and gave a verbal consent included in the study. Confidentiality of obtained information was assured.

\section{Field work}

Data were collected by the researcher, my husband and my brother during the period from the beginning of May to the end of July, 2013. Suitable time in the day was selected to ensure that large number of participants were acceptable. The interviews were held through poultry visits every day except Friday per weeks. The length of time required to complete each sheet depending on the response of the participants was about $20-30$ minutes. Every weeks about 33 sheets were finished. The researcher started data collection by introducing self to the workers then, the purpose of the study was explained to them to obtain their informed consent to participate in the study and to gain their cooperation. 


\section{Results}

Table (1): personal characteristics of the study participants at poultry farms, Assiut district, 2013.

\begin{tabular}{|c|c|c|}
\hline Socio-demographic characteristics of the study participants: & No. $(n=400)$ & $\%$ \\
\hline \multicolumn{3}{|l|}{ Age (years) } \\
\hline$<20$ & 72 & 18.0 \\
\hline $20-$ & 148 & 37.0 \\
\hline $30-$ & 113 & 28.2 \\
\hline 40 and above & 67 & 16.8 \\
\hline \multicolumn{3}{|l|}{ Marital status: } \\
\hline Married & 231 & 57.8 \\
\hline Single & 164 & 41.0 \\
\hline Widow & 5 & 1.2 \\
\hline \multicolumn{3}{|l|}{ Level of education: } \\
\hline Illiterate & 93 & 23.2 \\
\hline Read \& write & 62 & 15.5 \\
\hline Primary & 26 & 6.5 \\
\hline Preparatory & 53 & 13.2 \\
\hline Secondary & 161 & 40.2 \\
\hline University & 5 & 1.2 \\
\hline \multicolumn{3}{|l|}{ Type of work on poultry: } \\
\hline Chickens feed & 179 & 44.8 \\
\hline Clean farm & 171 & 42.8 \\
\hline Supervision of the farm & 167 & 41.8 \\
\hline Collect eggs & 117 & 29.2 \\
\hline Poultry transport to places of sale & 123 & 30.8 \\
\hline Manufacture of feed & 107 & 26.8 \\
\hline Connecting to the poultry cage & 101 & 25.2 \\
\hline Collect poultry transport & 100 & 25.0 \\
\hline Other* & 23 & 5.8 \\
\hline \multicolumn{3}{|l|}{ Number of working hours: } \\
\hline$>10$ hours & 254 & 63.5 \\
\hline $5-10$ hours & 146 & 36.5 \\
\hline \multicolumn{3}{|l|}{ Years of experience:(years) } \\
\hline$<5$ & 195 & 48.8 \\
\hline $5-$ & 70 & 17.5 \\
\hline $10-$ and above & 135 & 33.8 \\
\hline
\end{tabular}

Others : Security, Veterinarian, Driver 
Table (2): History of medical diseases among study participants at poultry farms, Assiut district, 2013.

\begin{tabular}{|c|c|c|}
\hline History of medical diseases & No. $(n=400)$ & $\%$ \\
\hline I-Respiratory diseases: & 69 & 17.2 \\
\hline \multicolumn{3}{|l|}{ *Type of respiratory diseases $(n=69)$} \\
\hline Bronchial asthma & 40 & 57.9 \\
\hline Bronchitis & 13 & 18.8 \\
\hline Hypersensitivity on the chest & 10 & 14.4 \\
\hline Tuberculosis & 5 & 7.2 \\
\hline Nasal sinusitis & 17 & 24.6 \\
\hline Lung fibrosis & 1 & 1.4 \\
\hline \multicolumn{3}{|l|}{ Duration of disease } \\
\hline$\geq 5$ years & 37 & 53.6 \\
\hline$<5$ years & 32 & 46.4 \\
\hline II-Skin disease & 23 & 5.8 \\
\hline \multicolumn{3}{|l|}{ *Type of diseases $(n=23)$} \\
\hline Tinea pedis & 13 & 56.5 \\
\hline Dermatitis & 8 & 34.8 \\
\hline Vitiligo & 7 & 30.4 \\
\hline \multicolumn{3}{|l|}{ Duration of disease: } \\
\hline$<5$ years & 14 & 60.9 \\
\hline$\geq 5$ years & 9 & 39.1 \\
\hline III-Musculoskeletal systems diseases: & 55 & 13.8 \\
\hline \multicolumn{3}{|l|}{ *Type of muscular diseases: $(n=55)$} \\
\hline Arthritis & 38 & 69.1 \\
\hline Orthoroartherosis & 6 & 10.9 \\
\hline Muscle strain & 25 & 45.4 \\
\hline The difficulty movement of the feet & 2 & 3.6 \\
\hline Roughness in the vertebrae & 2 & 3.6 \\
\hline Cruciform ligament & 1 & 1.8 \\
\hline Disc prolapsed & 3 & 5.4 \\
\hline \multicolumn{3}{|l|}{ Duration of disease: } \\
\hline$<5$ years & 41 & 74.5 \\
\hline$\geq 5$ years & 14 & 25.5 \\
\hline VI-Ophthalmic diseases: & 44 & 11.0 \\
\hline \multicolumn{3}{|l|}{ *Type of ophthalmic diseases: $(n=44)$} \\
\hline Eye inflammation & 27 & 61.3 \\
\hline Impairment of vision & 13 & 29.5 \\
\hline Sensitivity of the eye & 5 & 11.3 \\
\hline Corneal ulcer & 2 & 4.5 \\
\hline Cataract & 1 & 2.3 \\
\hline \multicolumn{3}{|l|}{ Duration of disease: } \\
\hline$<5$ years & 29 & 7.2 \\
\hline$\geq 5$ years & 15 & 3.8 \\
\hline \multicolumn{3}{|l|}{ X-Gastrointestinal diseases: } \\
\hline Yes & 25 & 6.2 \\
\hline \multicolumn{3}{|l|}{ *Type of gastrointestinal diseases: $(n=25)$} \\
\hline Diarrhea-gastroenteritis & 13 & 52.0 \\
\hline pepetic ulcer & 8 & 32.0 \\
\hline Inflammation of the esophagus & 5 & 20.0 \\
\hline Constipation & 2 & 8.0 \\
\hline \multicolumn{3}{|l|}{ Duration of disease: } \\
\hline$<5$ years & 21 & 84.0 \\
\hline$\geq 5$ years & 4 & 16.0 \\
\hline
\end{tabular}

*More than one answers 
Table (3): Distribute of the study participants correct knowledge about occupational health hazards at poultry farms, Assiut district, , 2013.

\begin{tabular}{|c|c|c|}
\hline Correct knowledge & No. $(n=400)$ & $\%$ \\
\hline Know & 160 & 40.0 \\
\hline \multicolumn{3}{|l|}{ *Occupational hazards: } \\
\hline \multicolumn{3}{|l|}{ 1- Biological hazards } \\
\hline Exposure to diseases & 144 & 90.0 \\
\hline \multicolumn{3}{|l|}{ 2-Chemical hazards } \\
\hline Exposure to dust & 84 & 52.5 \\
\hline Exposure to detergents and disinfectants & 76 & 47.5 \\
\hline \multicolumn{3}{|l|}{ 3-Accidents } \\
\hline Exposure to fracture & 53 & 33.1 \\
\hline \multicolumn{3}{|l|}{ 4-Physical hazards } \\
\hline Exposure to high levels of noise & 41 & 25.6 \\
\hline Exposure to burns & 46 & 28.8 \\
\hline \multicolumn{3}{|l|}{ * knowledge about risks from exposure to noise: } \\
\hline Hearing defect & 10 & 2.5 \\
\hline Psychotic disease & 8 & 2.0 \\
\hline Hypertensions & 7 & 0.8 \\
\hline Epilepsy & 2 & 0.2 \\
\hline Don't know & 378 & 94.5 \\
\hline \multicolumn{3}{|l|}{ Knowledge about risks from exposure to dust: } \\
\hline Yes & 56 & 14.0 \\
\hline \multicolumn{3}{|l|}{ Types of risks: } \\
\hline Respiratory disease & 38 & 67.9 \\
\hline Eye Disease & 18 & 32.1 \\
\hline
\end{tabular}

*More than one answer

Table (4): Distribute of the study participants correct knowledge about signs of sick birds at poultry farms Assiut district ,2013.

\begin{tabular}{|l|c|c|}
\hline \multicolumn{1}{|c|}{ Correct knowldge } & No. $(\mathbf{n}=\mathbf{4 0 0})$ & \% \\
\hline know & 217 & 54.2 \\
\hline *Signs of sick birds: $(\mathbf{n}=\mathbf{2}$ & \multicolumn{2}{|c|}{71.9} \\
\hline Diarrhea & 156 & 53.9 \\
\hline Difficulty of movement & 117 & 51.6 \\
\hline Loss of appetite & 112 & 44.7 \\
\hline Feathered loss & 97 & 44.7 \\
\hline Lack of production of eggs & 97 & 45.2 \\
\hline Change the shape of feathers & 98 & 44.2 \\
\hline Secretions from the mouth & 96 & 42.9 \\
\hline Swelling of the head & 93 & 39.6 \\
\hline Inconsistency movements & 86 & 2 \\
\hline
\end{tabular}

*More than one answer according the response of the study participants 
Table (5): Distribute of the study participants correct knowledge about zoonitic diseases transmitted from birds to human and modes of transmission at poultry farms Assiut district, 2013.

\begin{tabular}{|l|l|l|}
\hline \multicolumn{1}{|c|}{ Correct knowledge } & No. $(\mathbf{n}=\mathbf{4 0 0})$ & \% \\
\hline Know & 139 & 34.8 \\
\hline *Type of disease: $(\mathbf{n = 1 3 9})$ & 122 & 87.8 \\
\hline Avian Influenza & 74 & 53.2 \\
\hline Newcastle & 58 & 41.7 \\
\hline Tuberculosis birds & 38 & 27.3 \\
\hline Salmonella & 0 & 0.0 \\
\hline Chlamydophilosis & 0 & 0.0 \\
\hline Tuberculosis & 0 & 0.0 \\
\hline Campylobacteriosis & \multicolumn{2}{l|}{} \\
\hline Knowledge about the modes of transmission: $(\mathbf{n}=\mathbf{1 2 8})$ & 128 & 32.0 \\
\hline Know & \multicolumn{2}{l|}{} \\
\hline *Modes of transmission: & 76 & 59.4 \\
\hline Touching the bird secretion & 73 & 57.0 \\
\hline Direct contact with sick birds irregularities & 71 & 55.5 \\
\hline Direct contact with sick birds & 45 & 35.2 \\
\hline Eat sick birds & \multicolumn{2}{l|}{} \\
\hline
\end{tabular}

*more than one answer

Table (6): Practices of the study participants to avoid occupational health hazards at poultry farms, Assiut district, 2013.

\begin{tabular}{|c|c|c|c|c|}
\hline \multirow{2}{*}{ Hand washing: } & \multicolumn{2}{|c|}{ done } & \multicolumn{2}{|c|}{ Not done } \\
\hline & No. & $\%$ & No. & $\%$ \\
\hline Washing hands before and after egg collection & 50 & 12.5 & 350 & 87.5 \\
\hline Washing hands with soap and water with any antiseptic solution & 86 & 21.5 & 314 & 78.5 \\
\hline Washing hands with water and soap & 158 & 39.5 & 242 & 60.5 \\
\hline Washing hands with water only & 174 & 43.5 & 226 & 56.5 \\
\hline Drying hands after washing & 189 & 47.2 & 211 & 52.8 \\
\hline Washing hands after doing clean up the farm & 313 & 78.2 & 87 & 21.8 \\
\hline Washing hands after handling birds & 357 & 89.2 & 43 & 10.8 \\
\hline \multicolumn{5}{|l|}{ Wearing protective equipments*: } \\
\hline Wearing gloves during work & 22 & 5.5 & 378 & 94.5 \\
\hline Wearing a mask during work & 62 & 15.5 & 338 & 84.5 \\
\hline Wear protective head during you work & 80 & 20.0 & 320 & 80.0 \\
\hline Wear special shoes during working & 263 & 65.8 & 137 & 34.2 \\
\hline Wear especial clothes during work & 366 & 91.5 & 34 & 8.5 \\
\hline Close doors between you and chickens & 275 & 68.8 & 125 & 31.2 \\
\hline Clean clothes constantly used in the work & 297 & 74.2 & 103 & 25.8 \\
\hline Do eating and drinking inside the farm & 312 & 78.0 & 88 & 22.0 \\
\hline Cleaning the farm using detergents or disinfectants & 313 & 78.2 & 87 & 21.8 \\
\hline
\end{tabular}

*There is more than one answer 
Table (7) : Relations between attitude score of study participants and personal characteristic at poultry farms, Assiut district, 2013.

\begin{tabular}{|c|c|c|c|c|c|}
\hline & \multicolumn{4}{|c|}{ Attitude score } & \multirow{3}{*}{ P-value } \\
\hline & \multicolumn{2}{|c|}{ Negative $(n=261)$} & \multicolumn{2}{|c|}{ Positive $(n=139)$} & \\
\hline & No. & $\%$ & No. & $\%$ & \\
\hline \multicolumn{5}{|l|}{ Age (years) } & \multirow{5}{*}{0.295} \\
\hline$<20$ & 40 & 55.6 & 32 & 44.4 & \\
\hline $20-$ & 99 & 66.9 & 49 & 33.1 & \\
\hline $30-$ & 46 & 68.7 & 21 & 31.3 & \\
\hline 40 and above & 76 & 67.3 & 37 & 32.7 & \\
\hline \multicolumn{5}{|l|}{ Level of education: } & \multirow{5}{*}{$0.022^{*}$} \\
\hline Secondary & 97 & 58.4 & 69 & 41.6 & \\
\hline Basic education & 50 & 63.3 & 29 & 36.7 & \\
\hline Illiterate & 65 & 69.9 & 28 & 30.1 & \\
\hline Read \& write & 49 & 79.0 & 13 & 21.0 & \\
\hline \multicolumn{5}{|l|}{ Years of experience: } & \multirow{4}{*}{0.300} \\
\hline$<5$ & 122 & 62.6 & 73 & 37.4 & \\
\hline $5-$ & 88 & 65.2 & 47 & 34.8 & \\
\hline 10 and above & 51 & 72.9 & 19 & 27.1 & \\
\hline
\end{tabular}

Figure (1) : total scoring attitude of the studied sample about occupational health hazards at poultry farms Assuit district.

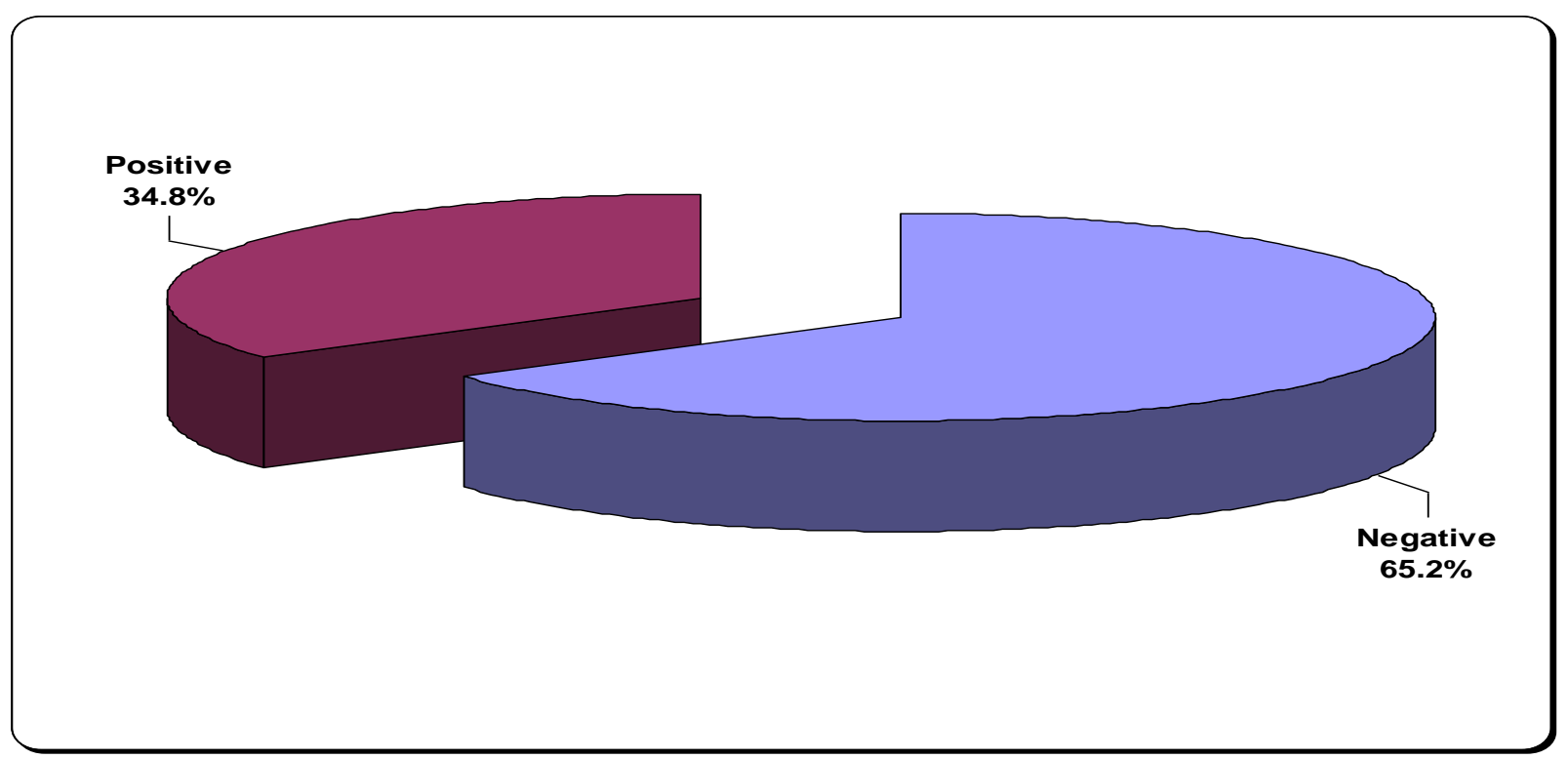

Table(1) : shows the personal characteristics of the study participants. Regarding their age, it was noticed that more than one third $(37.0 \%)$ of the workers aged between 20 years and less than 30 years followed by $28.2 \%$ of study sample the workers aged more than 40 years. More than half of the workers were married(57.8\%). As regarding level of education, $40.2 \%$ had secondary education followed by $23.2 \%$ were illiterates.
Table(2) : illustrates history of medical diseases among study participants at poultry farms. It reveals that $17.2 \%$ of the studied sample suffered from respiratory diseases. More than half $(57.9 \%)$ of them complained from asthma. 5.8\% of the workers complained from skin disease and more than half $(56.5 \%)$ of them affected by tinea pedis. More than two thirds of them (69.1\%) complained from arthritis and $1.8 \%$ complained from cruciform ligament. $11.0 \%$ of the studied sample suffered from 
ophthalmic diseases, $61.3 \%$ of them mentioned that they had eye inflammation while $6.2 \%$ suffered from digestive system disorders .

Table(3) : reveals knowledge of the study participants about occupational health hazards. As observed from the table, $40.0 \%$ had correct knowledge about occupational health hazards at poultry farms. The vast majority $(90.0 \%)$ of them mentioned exposure to disease were occupational hazards at poultry farms followed by more than half $(52.5 \%)$ exposure to dust. The vast majority of them $(94.5 \%)$ did not know risks of exposure to noise while $2.5 \%$ stated that risks were hearing defect.

Table(4) : shows knowledge of the study participants about signs of sick birds at poultry. It reveales that more than half $(54.2 \%)$ of the studied sample had correct knowledge about a signs and a symptoms of sick birds. $71.9 \%$ of them mentioned that diarrhea is a signs and a symptoms of sick bird. more than one third (39.6\%) mentioned that lack and inconsistency movements.

Table(5) : illustrates knowledge the study participants about zoonitic diseases transmitted from birds to human and modes of transmission. More than one third ( $34.8 \%$ ) of the studied sample had knowledge about the disease transmission from birds to human. The majority $(87.8 \%)$ of them mention avian influenza can transmitted from birds to human followed by more than half (53.2\%) mentioned Newcastle disease. It was found that $32.0 \%$ of the studied sample had knowledge about the ways of transmission from birds to human. More than half $(59.4 \%)$ mentioned that touching the bird secretions also $57.0 \%$ mentioned that direct contact with sick bird.

The results in

Table (6) : It reveals that the majority (89.2\%) of the studied sample washing hand after handling birds but $43.5 \%$ of them washing hand with water only. The vast majority $(91.5 \%)$ of the studied sample wearing special clothes during work. while about two thirds $(65.8 \%)$ of them wearing special shoes during work. Also show $78.2 \%$ of them cleaning the farm by using detergents or disinfectants.

Table (7) shows relation between workers attitude score and their personal characteristic at poultry farms in Assiut district. It shows there is no statistical significant difference between their attitude and age \& years of experience P- value (0.295 \& 0.300). Also show there is statistical significant difference between attitude and level of education $\mathrm{P}$ - value $(0.022)$

Figure (1) : total scoring attitude of the studied sample about occupational health hazards at poultry farms Assuit district. It reveals that $34.8 \%$ of studied sample had positive attitude while $65.2 \%$ of them had negative attitude.

\section{Discussion}

Commercial poultry production is a dusty business. Poultry farm workers are exposed to high concentrations of airborne dust ranging from a single substance, e.g. wood dust, to a complex mixture which might include inorganic and organic material derived from feed, litter, faecal material, dander (skin material), feather and micro-organisms which could cause respiratory diseases including asthma and chronic bronchitis( Liebers et al, 2007).

The findings of the present study showed that As regards the personal characteristics of the studied sample, about two thirds $(65.2 \%)$ of them were aged between 20- 40 years. This finding agrees with the findings of (Adedeji et al, 2011) who found that more than half $(55 \%)$ of the studied sample who worked in poultry farms were aged between 21-40 years. On the other hand, this finding disagrees with (Yu et al, 2013) who found that 24.9\% were 18-35 years, and $26.9 \%$ were more than 45 years. This implies that youths are mostly engaged at poultry farming in the study area more than elderly people.

Concerning their marital status, more than half $(57.8 \%)$ of the studied sample were married. This finding is nearly similar to the results of (Ismail and Ahmed, 2010) who found in their study that 50.6\% of the studied sample was married.

The study found that respondents who finished secondary school had the highest percentage (40.2\%) while $23.2 \%$ of them were illiterates. The current results are consistent with those of (Adedeji, et al, 2011) who reported that the $46.1 \%$ of the studied sample finished secondary education. On the other hand, $1.2 \%$ of them received university education, $15.5 \%$ of them could read and write, and only $6.5 \%$ of them finished primary school. This implies that people who finished secondary school are mostly engaged at poultry farming in the study area.

Concerning the type of work, $(44.8 \%, 42.8 \%$ and $29.2 \%$ ) of studied sample engaged in chickens feed, cleaning of poultry and collecting eggs. This finding disagrees with( Fatiregun and Saanipp, 2008) who found that $82.1 \%, 65.7 \%$ and $62.9 \%$ of the studied sample engaged in feeding poultry, sweeping poultry and collecting eggs, respectively. This finding can be accounted for by the fact that most workers in our study area engaged in all types of work at poultry farms rather than specific work.

Regarding years of work, it was observed that nearly half $(48.8 \%)$ of the studied sample had job experience of less than 5 years. This finding disagrees with( Cahyadi, 2010) who found that 
$19.0 \%$ had job experience of less than 5 years. On the other hand, our study shows that more than one third $(33.8 \%)$ of them had job experience more than 10 years. This finding is in line with those of (Cahyadi, 2010) who found that $33.0 \%$ of the workers had job experience more than 10 years.

Concerning respiratory diseases, (Health Safety and Executive, 2008) reported that respiratory disease is a major occupational health risk for those working in farms, with an incidence of occupational asthma several times the national average. Research suggests that working at poultry housings is associated with higher exposures to organic dusts than for cow or swine housing and the prevalence of symptoms among poultry workers is also higher. The present study showed that $17.2 \%$ of the studied sample were suffering from respiratory disease. This finding is nearly similar to the result of (Quandt et al, 2006) who found that $14.5 \%$ of their study sample were suffering from respiratory disease. On the other hand, this finding disagrees with (El-Saadawy et al, 2011) who found that $41.8 \%$ of their studied sample complained from respiratory symptoms. This finding can be accounted for by the small size of our study sample and the production of chicken feeding outside the poultry.

Concerning skin diseases, $5.8 \%$ of the studied sample had skin disease. More than half $(56.5 \%)$ of them stated that they were suffering from tinea pedis. This finding is nearly similar to the result of (Odunsi et al, 2005) who found that $8.2 \%$ of their studied sample stated that they were suffering from skin diseases. On the other hand, this finding disagrees with (Quandt et al, 2006) who found that $21.4 \%$ of their studied sample were suffering from skin diseases. It also disagree with ( El-Saadawy et al, 2011) who found that $38.1 \%$ of the workers had skin diseases. (North Carolie State University, 2002) reported that conditions in poultry plants expose workers to multiple agents affecting the skin. The number of skin ailments was expected to be high. Each worker had at least one dermatological diagnosis.

Regarding musculoskeletal diseases, $13.8 \%$ of the studied sample complained from musculoskeletal diseases. $69.1 \%$ of them were suffering from arthritis. This may be explained by the musculo-skeletal disorders that could be caused by the activity of pulling birds from cages in the narrow aisles of a battery house, lifting heavy loads and exposure to cold and heat in poultry farms ( Donham , 2000).

The findings of present study showed that $11.0 \%$ of the studied sample were suffering from ophthalmic disease. less than two thirds (61.3) complained from eye inflammation. This finding disagrees with ( ElSaadawy et al, 2011) who found that $22.7 \%$ of their studied sample had eye inflammation. This disagreement is accounted for by our study sample's exposure to sand dust in the mountainous area of poultry farms and to feeding and also by workers not wearing eye protection during work.

Concerning digestive system diseases, $6.2 \%$ of the studied sample were suffering from digestive system diseases. The findings of the current study disagree with those of (Quandt, et al, 2006) who reported that $19.8 \%$ of their studied sample had digestive system diseases. This disagreement can be accounted for by the fact some workers of our study sample at poultry farms were exposed to contamination because of lack of knowledge about the importance of hand washing after dealing with chickens.

Regarding knowledge about occupational health hazards in poultry farms, $40.0 \%$ of the studied sample had correct knowledge. The vast majority (90.0\%) reported exposure to disease from occupational health hazards in poultry farms. This finding disagrees with (Adedji et al, 2011) who found that $46.7 \%$ of the studied sample reported exposure to disease. On the other hand, the current study showed that $47.5 \%$ of the workers under study reported occupational health hazards due to exposure to disinfectants. This finding is in line with (Adedji et al, 2011) who found that $38.3 \%$ of the workers mention exposure to disinfectants. Also in our study $28.8 \%$ of the workers mention exposure to burns. This finding disagrees (Adedji et al, 2011) who found that $1.7 \%$ of the workers mention exposure to burns.

The results of the present study also reveal that the general level of workers' knowledge about the signs and symptoms of disease. More than half $(54.2 \%)$ of the studied sample had correct knowledge. 71.9 of them stated that diarrhea is one of the signs and symptoms of disease. This result disagrees with (Al shehri, et al, 2006) who found that $20.8 \%$ of the workers mentioned that diarrhea is a symptom of disease. On the other hand, in our study $53.9 \%$ of the studied sample mentioned that sick birds had difficulty moving. This found is in line with (Ismail and Ahmed, 2010) who found that $66.1 \%$ of the workers mentioned that sick birds had difficulty moving, while in our study $44.7 \%$ of the workers reported loss of feathers. This finding disagrees with (Ismail and Ahmed, 2010) who found that $19.5 \%$ of the workers reported loss of feathers. The results of the present study also show that $44.7 \%$ of the workers reported reduced egg production. This finding disagrees with (Ismail and Ahmed, 2010) who found that $27.0 \%$ of their study sample reported reduced egg production as a sign of sick birds.

Regarding workers' knowledge about zoonitic disease (bird), the current study indicated that more than one third $(34.8 \%)$ of the studied sample had 
correct knowledge about zoonitic diseases. The majority $(87.8 \%)$ of them mentioned that zoonitic diseases and avian influenza at poultry farms could be transmitted to human while more than half $(53.2 \%)$ mentioned that Newcastel disease. Also the present study shows that more than one third (41.7\%) mentioned tuberculosis.

As regards workers' knowledge of the modes of transmission, the current study showed that less than one third $(32.0 \%)$ of the respondents had knowledge of the modes of transmission to humans. More than half $(59.4 \%)$ of the respondents reported that disease could be transmitted to human by touching the bird's secretion, while $57.0 \%$ stated that human could be infected through direct contact with sick birds' secretion. This finding does not agree with (Abbate et al, 2006) who found that less than two thirds $(65.0 \%)$ of the studied sample stated that diseases could be transmitted to human through touching the birds' secretion and $90.3 \%$ of them stated that diseases could be transmitted through touching the bird.

As regards the practice of washing hands with water and soap, the present found that more than one third $(39.5 \%)$ of the studied sample reported using this practice. This finding is consistent with a KAP study conducted in Ain Shams by (Al shehri et al, 2006) where more than one third $(36.5 \%)$ of the respondents washed their hand with soap and water. On the other hand, in our study the majority $(89.2 \%)$ of the sample washed hands after dealing with birds. This finding also agrees with a KAP (Knowledge, Attitudes and Practices) study conducted in Ain Shams by (Al shehri et al, 2006) who found that $75.7 \%$ of the sample washed hands after dealing with birds.

The current study illustrated that vast majority $(91.5 \%)$ of the studied sample wore especial clothing during work, which agrees with a KAP study conducted in China by (Yu et al, 2013) which found that $88.9 \%$ of the study sample wore special clothing during work. On the other hand, in our study less than two thirds $(65.8 \%)$ of the studied sample wore boots during work. The present study also agrees with a KAP study conducted in Nigera by (Fatireagun and Saanipp, 2008) who found that more than two thirds $(67.9 \%)$ of the study sample wore boots during work to decrease exposure to hazards.

As regards practices of wearing a mask during work, the current study found that only $15.5 \%$ of the study sample wore masks. This result is consistent with a KAP study conducted in Nigera by (Fatiregun and Saanipp, 2008) who found that $11.4 \%$ of their study sample wore masks during work while in our study only $5.5 \%$ of the sample wore gloves during work. This finding disagrees with the KAP study conducted in Nigera by (Fatiregun and Saani, 2008) who reported that $10.7 \%$ of their study sample wore gloves during work.

The study reveals that there is no statistically significant difference between workers' attitude and their age. This finding disagrees with (Ismail and Ahmed, 2010) who reported that workers' age affected their attitude and that there is statistically significant difference $(\mathrm{p}<0.05)$.

The present study also shows that there is no statistically significant difference between workers' attitude and their level of education and years of experience $(\mathrm{p}=0.0022,0.300)$. This means that age and years of experience did not affect the attitudes of workers.

\section{Conclusion}

Based on the results of the present study, $17.2 \%$ from study participants suffer from respiratory disease. $40.0 \%$ had correct knowledge about occupational hazards. There is statistical a significant difference between level of knowledge and age of workers characteristics A significant difference was found between score of knowledge and attitude.

\section{Recommendations}

Based on the results of the present study, it was recommended

1-Workers must wear appropriate personal protective equipment such as gloves, mask and aprons.

2-Wearing special clean clothes, and disinfecting boots before and after visiting chicken houses.

3-Washing hands with soap and warm water before and after leaving the chicken house, and drying hands with disposable towels.

4-Training workers on correct bird handling techniques .

5-The workers in poultry farms should have a periodical medical follow -up and investigation to maintain health.

\section{Reference}

1. Abbate R,Giuseppe G., Marinelli P., and Angelillo I., (2006): Knowledge, Attitudes, and Practices of Avian Influenza, Poultry Workers, Italy Emerging Infectious Diseases • www.cdc.gov/eid • Vol. 12, No. 11, November 2006 pp 1762-1765.

2. Abdelwhab E., \& Hafez H., (2011) : An overview of the epidemic of highly pathogenic H5N1 avian influenza virus in Egypt: epidemiology and control challenges. Epidemiol Infect 2011, 139: pp 647-657. 
3. Al-Shehri A., Abdel-Fattah M., and Hifnawy T(2006): Knowledge and concern about avian influenza among secondary school students in Taif, Saudi Arabia. Eastern Mediterranean Health Journal. (Supplement 2) S178-S88.

4. Adedeji I., Olapade-Ogunwole F., Farayola C., \& Adejumo I., (2011): Productivity Effects of Occupational Hazards among Poultry Farmers and Farm Workers in Osogbo Local Government Area of Osun State. International Journal of Poultry Science 10 (11):pp 867-870.

5. BLS (Bureau of Labor Statistics). (2007): Incidence rates of nonfatal occupational injuries and illnesses by industry and case types, 2006.http://stats.bls.gov/iif/oshwc/osh/os/ostb17 65.pdf. Accessed: November 26, 2008.

6. Caracciolo, F., Coppola, A., and Verneau, F., (2011): Validation of psychometric scale to measure consumers' fears of modern food technologies. International European Forum on System Dynamics and Innovation in Food Networks, International European Forum, February 14-18, 2011, Innsbruck-Igls, Austria.[Accessed on 1 April 2012] http://purl.umn.edu/122005.pp160-174

7. Cahyadi Y., (2013): Highly pathogenic avian influenza knowledge, attitude, and practices study among live bird market workers in Jakarta pp1-142

8. Donham K., (2000): 'Dose-response relationships between occupational aerosol exposures and cross-shift declines of lung function in poultry workers: Recommendations for exposure limits' Journal of Occupational and Environmental Medicine 200042 PP 260-269.

9. El-saadawy M., Nassif M., abou Elmaged S., \& Ahmed A., (2011): Some Occupational Health Problems among Poultry Farm Workers in Sharkia Governorate: An Epidemiological Study Journal of American Science, 2011;7(11) http://www.americanscience.org pp 37- 43

10. Fatiregun A., \& Saanipp M., (2008): Knowledge, attitudes and compliance of poultry workers with preventive measures for avian influenza in Lagelu, Oyo State, Nigeria Original Article pp 130-134.

11. HSE (Health Safety and Executive) books (2008): Exposure to dust and bioaerosols in poultry farming: Summary of observations and data

RR655

www.hse.gov.uk/research/rrhtm/index.htm

12. Ismail N., \& Ahmed H., (2010): Knowledge, Attitudes and Practices Related to Avian Influenza among a Rural Community in EgyptEgypt Public Health Assoc, Vol. 85 No. 1 \& 2,2010 pp 74- 96
13. Ismail N., \& Ahmed H., (2010): Knowledge, Attitudes and Practices Related to Avian Influenza among a Rural Community in EgyptEgypt Public Health Assoc, Vol. 85 No. 1 \& 2,2010 pp 74- 96

14. Liebers V., Raulf-Heimsoth M., Linsel G., Goldscheid N., Düser M., Stubel H., \& Brüning T (2007): Evaluation of quantification methods of occupational endotoxin exposure. J Toxicol Environ Health A. 70:1pp 798-805.

15. Mary A., Nies, (2011) community public health nursing promoting the the health of population fourth edition pp $610-613$.

16. NC State University (2002): Improving the health and safety of poultry facility workers. Available at http//www.bae.ncsu.e du/programs/extension/index.html

17. Odunsi, A., Togun and Oladunjoye, I., (2005) Introduction to animal productions and processing. First publisher Ibadan. Nigeria, pp: 35.

18. Occupational Safety \& Health Administration(OSHA), 2007): Safety and health topics: respiratory protection. Washington, DC: U.S. Department of Labor, Occupational Safety and Health Administration. www.osha.gov/SLTC/respiratoryprotection/inde X.html

19. Quandt S., Grzywacz J., Mann A., Carrillo L., Coates M., Burke B., \& Arcury T., (2006): Illnesses and Injuries Reported by Latino Poultry Workers in Western North Carolina American Journal Of Industral Medicine49:pp 343-351

20. Wei H., Bai G., Mweene A., Zhou Y., Congyl, P., Wang S., Kida H., \& Liu J., ( 2006):. Rapid detection of avian influenza virus $A$ and subtype H5N1 by single step multiplex reverse transcription-polymerase chain reaction.VIRUS GENES. 32:261-7. 